\title{
The Relationship of Mutation Carriage of BRCA1/2 and Family History in Triple-Negative Breast Cancer: Experience from a Diagnostic Center in Turkey
}

\author{
(D) Neslihan Duzkale ${ }^{1}$, (D) Olcay Kandemir ${ }^{2}$ \\ ${ }^{1}$ Department of Medical Genetic, University of Health Sciences Turkey, Ankara Dışkapı Yıldırım Beyazıt Training and Research Hospital, Ankara, Turkey \\ ${ }^{2}$ Clinic of Medical Pathology, Dr. Abdurrahman Yurtaslan Ankara Oncology Training and Research Hospital, Ankara, Turkey
}

\begin{abstract}
Objective: $B R C A 1 / 2$ genes play a role in the etiopathogenesis of $10 \%-30 \%$ of triple-negative breast cancer (TNBC). This study aims to investigate the $B R C A 1 / 2$ genes and the demographic and clinicopathological features in patients with TNBC. The study also examined the impact of cancer history of TNBC individuals' relatives on the risk of $B R C A 1 / 2$ mutation carriership rate.

Materials and Methods: The BRCA1/2 genes of 65 women diagnosed with TNBC between 2011 and 2017 were investigated using next-generation sequencing. We analyzed the correlations of patients' demographic and clinicopathologic parameters and family history with $B R C A 1 / 2$ mutation status. We used the $\chi^{2}$-test, $\mathrm{t}$-test, Mann-Whitney $\mathrm{U}$ test, and logistic regression statistical methods.

Results: The BRCA1/2 mutation carrier rate was $16.9 \%$. Patients who had BRCA1/2 mutations were compared with those who did not in terms of demographic and clinicopathological parameters. In the BRCA1/2 mutation carrier group, the Ki-67 index and the number of relatives with cancer were higher than the $B R C A 1 / 2$ non-carrier group. Logistic regression analysis revealed that when the number of relatives with breast or ovarian cancer was $\geq 2$, the risk of carrying the $B R C A 1 / 2$ mutation increased by 15 -fold. Regardless of the type of cancer (including cancers in other organs besides breast or ovary), the risk of carrying the BRCA1/2 mutation increased 1.3 times with each increase in the number of relatives with cancer for the patient with TNBC.

Conclusion: In cases with a diagnosis of TNBC, a significant relationship exists between the number of relatives with cancer in the family history and the risk of carrying mutations in the BRCA1/2 genes. This relationship can be confirmed further by large-scale studies with more cases.
\end{abstract}

Keywords: $B R C A 1 / 2$, family history, hereditary cancer, triple-negative breast cancer

Cite this article as: Duzkale N, Kandemir O. The Relationship of Mutation Carriage of BRCA1/2 and Family History in Triple-Negative Breast Cancer: Experience from a Diagnostic Center in Turkey. Eur J Breast Health 2021; 17(2): 137-144

\section{Key Points}

- $\quad$ TNBC type breast cancers are frequently seen in BRCA1/2 genes mutation carriers.

- The Ki67 index of $B R C A 1 / 2$ gene mutation carriers is high in TNBC.

- In TNBC, the family cancer history is important at the risk of BRCA1/2 carriage.

\section{Introduction}

Breast cancer is the most common type of cancer in females worldwide, and it is the most common cause of cancer-related death in females (1). Triple-negative breast cancer (TNBC) constitutes approximately $12 \%-24 \%$ of breast cancers, highly heterogeneous regarding clinical behavior, morphological features, and genetic background (2). The TNBC subtype is more commonly seen in certain ethnic groups (like African-American, and Hispanic), and BRCA1/2 gene mutation carriers are often diagnosed as intermediate cancer (3). TNBC has a poor prognosis than other breast cancers in terms of relapse rate, frequency of metastasis, and survival parameters. The expression of estrogen receptors (ER) and progesterone receptors (PR) and amplification of HER2 have not been observed in these cancers in analyzes performed using immunohistochemisty. Therefore, endocrine therapies or anti-HER2 therapies cannot be used in these patients (4). Genetic causes play an essential role in the etiopathogenesis of TNBC. The best-known genetic risk factors are BRCA1/2 mutations, which lead to hereditary breast and ovarian cancer syndrome. These genes are involved in controlling the cell cycle, chromatin remodeling, and epigenetic regulation. Loss of function mutations in these tumor suppressor genes, which are important for the continuation of genomic integrity, contribute to initiating carcinogenesis. The prevalence of carrying BRCA1/2 mutations has been reported as 3\% in all breast cancer patients and $10 \%-30 \%$ in TNBC patients (5). Approximately $70 \%$ 
of breast cancers are observed in $B R C A 1$ germline mutation carriers, and $16 \%-23 \%$ of breast cancers in $B R C A 2$ germline mutation carriers are the TNBC subtype (6-7). This single-center cohort study aims to evaluate the relationship between the BRCA1/2 mutation status and demographic characteristics, clinicopathological details, and family cancer histories of 65 patients diagnosed with TNBC.

\section{Materials and Methods}

In this study, 65 Turkish female patients with TNBC from the Dr. Abdurrahman Yurtaslan Ankara Oncology Training and Research Hospital, Department of Medical Genetics, were investigated between 2011 and 2017 for their breast cancer's genetic etiology. BRCA1/2 test standards were applied to the patients in accordance with the National Comprehensive Cancer Network Guidelines (8). They were over 18 years old, and their breast cancers were diagnosed as the primary tumor. The patients' family history was evaluated by examining at least three generations of pedigree analyses. This study was conducted by considering ethical responsibilities according to the Declaration of Helsinki and approved by the independent Ethics Committee of the Dr. Abdurrahman Yurtaslan Ankara Oncology Training and Research Hospital approved this study (no: 2020-02/536). In this study, all patients were informed about genetic tests and the use of their information, and their consent was obtained.

All patients' breast cancer was histologically confirmed, and staging was determined based on the sixth edition of the American Joint Committee on Cancer (9). If the percentage of cells stained positive by immunohistochemistry was less than $1 \%$, the ER and PR status was evaluated as negative. For HER2 gene amplification in IHC staining, membranous staining was graded from 0 to +3 . Patients with a staining pattern of +2 were evaluated using the fluorescent in situ hybridization method. Those with $<2$ copies of the HER2 gene were considered negative.

Patients' genetic analyzes were conducted on the Ion $S 5^{\mathrm{TM}}$ platform with the next-generation sequencing method and used the Oncomine ${ }^{\mathrm{TM}}$ $B R C A$ Research Assay kit. In the analysis, all the coding regions of $B R C A 1 / 2$ genes and the part containing the 25 base pairs of exonintron junctions were investigated. The presence of genomic copy number changes in patients was also investigated using a Multiplex ligation-dependent probe amplification method. The Ion Reporter Software Version 5.4 program was used in the bioinformatics analysis of the obtained data. For BRCA1 and BRCA2 genetic analysis, the accession numbers used were NM_007294.3 and NM_000059.3, respectively. Sequence variants were classified using algorithms in the American College of Medical Genetics and Genomics guideline (10).

SPSS (IBM SPSS Statistics 24) program was used in the statistical evaluation of all results. In this study, the $\chi^{2}$-test, t-test, MannWhitney $\mathrm{U}$ test and logistic regression analysis were used, and $\mathrm{p}<0.05$ was considered statistically significant.

\section{Results}

The mean age of diagnosis of 65 patients included in this study was $41 \pm 10$ years. Most patient $(73.9 \%)$ visits were due to a palpable mass when a cancer diagnosis was made. Of these patients, TNBC was grade 3 in $50 \%$, invasive ductal carcinoma in $80 \%$, and approximately $1-3 \mathrm{~cm}$ mass in $72 \%$. The demographic and clinicopathological characteristics of these 65 patients are presented in Table 1 . Women considered positive. In the oral contraceptive usage parameter, patients' use for five years and longer was positive. Among the relatives of patients in the study group, 20 different types of cancer were detected, including breast, ovarian, endometrium, colon, stomach, liver, biliary tract, lung, laryngeal, bladder, kidney, brain, leukemia, lymphoma, oral, skin, and thyroid cancers. The most common cancers among the relatives were breast, lung, colon, stomach, larynx, prostate, and uterus cancers (Figure 1). In the grouping of relatives diagnosed with cancer, the number of relatives diagnosed with breast and ovarian cancer and the relatives who were diagnosed with any cancer, regardless of the cancer type was determined from pedigree analysis. In our study, the total prevalence of $B R C A 1 / 2$ mutations evaluated was $16.9 \%(11 / 65)$. Of BRCA1/2 mutations, $63.6 \%$ were in BRCA1 (7/11), and $36.4 \%$ were in $B R C A 2$ (4/11). The majority of $B R C A 1$ mutations were of the nonsense type, whereas all $B R C A 2$ mutations were of the frameshift type. All mutations were detected in the heterozygous state. Two of these mutations have not been reported before (Table 2). Patients with and without $B R C A 1 / 2$ pathogenic variants were compared statistically regarding demographic and clinicopathological features (Table 3). In the group with the $B R C A 1 / 2$ mutation, the Ki-67 index and the number of relatives with cancer were higher than $B R C A 1 / 2$ mutationnegative group. When other parameters were investigated, no statistically significant difference was found between the groups. The mean Ki-67 index of all patients in the study was 53 (range: 5-100). This Ki-67 index was 78 in the BRCA1/2 mutation carrier group and 40 in $B R C A 1 / 2$ mutation-negative group. The difference between these two groups was statistically significant $(\mathrm{p}=0.022)$ (Table 4$)$. Logistic regression analysis was performed to investigate the association of BRCA1/2 mutation carrier status and the number of relatives with breast and ovarian cancer. There was a significant relationship between the number of relatives with cancer and BRCA1/2 mutation carrier status $(\mathrm{p}=0.006)$. Those who have two or more relatives with cancer had a 15 times higher risk of carrying a disease-related variant in BRCA1/2 than those without cancer relatives (Table 5). A logistic regression analysis was also performed to investigate the relationship between $B R C A 1 / 2$ mutation status and all relatives with cancer regardless of the cancer type. In this model, a significant correlation was found ( $\mathrm{p}=0.047)$. The risk of BRCA1/2 mutation carrier status means 1.3 times increased risk for cancer among the relatives (Table 6).

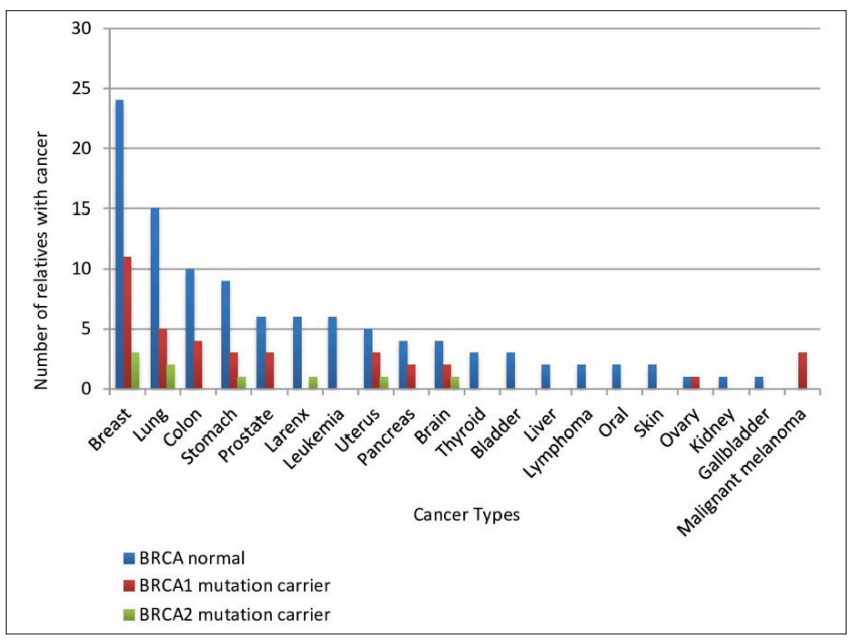

Figure 1. Types of cancer in relatives and the distribution percentages between those with and without BRCA mutations

BRCA: Breast cancer susceptibility genes 
Table 1. Baseline patient demographics and clinicopathological details

\begin{tabular}{|c|c|c|c|}
\hline \multicolumn{2}{|c|}{ Characteristics $(n=65)$} & \multirow{2}{*}{$\begin{array}{c}\mathbf{n} \\
23\end{array}$} & \multirow{2}{*}{$\begin{array}{l}\text { \% } \\
35\end{array}$} \\
\hline Age & $\leq 40$ & & \\
\hline$X \pm S D \rightarrow 45.09 \pm 10.38,($ years) & $>40$ & 42 & 65 \\
\hline Age at diagnosis & $\leq 40$ & 34 & 52 \\
\hline$X \pm S D \rightarrow 40.86 \pm 10.28,($ years) & $>40$ & 31 & 48 \\
\hline \multirow{2}{*}{$B R C A 1 / 2$ mutation status } & Non-carriers & 54 & 83 \\
\hline & Carriers & 11 & 17 \\
\hline \multirow{2}{*}{ Residence } & Rural & 11 & 17 \\
\hline & City & 54 & 83 \\
\hline & Elementary school & 27 & 42 \\
\hline \multirow[t]{2}{*}{ Level of education } & High school & 22 & 33 \\
\hline & University & 16 & 25 \\
\hline \multirow[t]{2}{*}{ Working status } & No & 41 & 63 \\
\hline & Yes & 24 & 37 \\
\hline \multirow{3}{*}{ Marital status } & Single & 7 & 11 \\
\hline & Married & 58 & 89 \\
\hline & No & 11 & 17 \\
\hline \multirow[t]{2}{*}{ Number of children } & Up to 4 & 50 & 77 \\
\hline & $\geq 4$ & 4 & 6 \\
\hline \multirow{3}{*}{ Smoking } & No & 51 & 79 \\
\hline & Yes & 14 & 21 \\
\hline & No & 54 & 83 \\
\hline \multirow[t]{2}{*}{ Oral contraceptive use (years) } & $1-5$ & 7 & 11 \\
\hline & $\geq 5$ & 4 & 6 \\
\hline \multirow{2}{*}{ Chronic disease } & No & 44 & 68 \\
\hline & Yes & 21 & 32 \\
\hline \multirow{3}{*}{ Menopause status } & Premenopause & 40 & 62 \\
\hline & Postmenopause & 25 & 38 \\
\hline & No & 16 & 25 \\
\hline \multirow[t]{2}{*}{ Family history of all types of cancers } & $\leq 2$ & 27 & 42 \\
\hline & $\geq 3$ & 22 & 33 \\
\hline \multirow{3}{*}{ Family history of breast/ovarian Ca } & Breast & 25 & 38 \\
\hline & Ovarian & 20 & 31 \\
\hline & Right & 34 & 52 \\
\hline \multirow[t]{4}{*}{ Tumor localization } & Left & 30 & 46 \\
\hline & Bilateral & arr1 & 2 \\
\hline & Palpable mass (right) & 23 & 35 \\
\hline & Palpable mass (left) & 25 & 39 \\
\hline \multirow[t]{4}{*}{ The first symptome of Ca } & Swelling, disfigurements, nipple discharge (right) & 2 & 8 \\
\hline & Swelling, disfigurements, nipple discharge (left) & 5 & 6 \\
\hline & Routine check & 8 & 12 \\
\hline & $\leq 2$ & 28 & 43 \\
\hline \multirow[t]{2}{*}{ Tumor size (cm) } & $>2$ & 36 & 55 \\
\hline & Multifocal & 1 & 2 \\
\hline
\end{tabular}


Table 1. Continued

\begin{tabular}{|c|c|c|c|}
\hline \multicolumn{2}{|r|}{ Characteristics $(n=65)$} & \multirow{2}{*}{$\begin{array}{c}\mathbf{n} \\
28\end{array}$} & \multirow{2}{*}{$\begin{array}{l}\% \\
43\end{array}$} \\
\hline \multirow{3}{*}{ Tumor size $(\mathrm{cm})$} & $\leq 2$ & & \\
\hline & $>2$ & 36 & 55 \\
\hline & Multifocal & 1 & 2 \\
\hline \multirow{7}{*}{ Histopathology } & Invasive ductal carcinoma & 52 & 80 \\
\hline & Musinoz carcinoma & 2 & 3 \\
\hline & Metaplastic carcinoma & 3 & 5 \\
\hline & Medullary carcinoma & 4 & 6 \\
\hline & Apocrine carcinoma & 1 & 2 \\
\hline & Invasive lobular carcinoma & 1 & 2 \\
\hline & Others & 2 & 4 \\
\hline \multirow{3}{*}{ Tumor grade } & 1 & 2 & 3 \\
\hline & 2 & 13 & 20 \\
\hline & 3 & 50 & 77 \\
\hline \multirow{5}{*}{ Ki-67 } & $>60$ & 22 & 34 \\
\hline & $41-60$ & 7 & 11 \\
\hline & $21-40$ & 19 & 29 \\
\hline & $\leq 20$ & 9 & 14 \\
\hline & No available data & 8 & 12 \\
\hline \multirow{3}{*}{ Metastases at the diagnosis } & No & 41 & 63 \\
\hline & Lymph node & 22 & 34 \\
\hline & Distant sites (lung, brain) & 2 & 3 \\
\hline
\end{tabular}

\section{Discussion and Conclusion}

TNBC is a breast cancer subtype with clinically aggressive behavior and poor prognosis with limited treatment options and poor overall and disease-free survival. This cancer type is extremely heterogeneous regarding clinical, genetic, and histopathologic features. In this cohort study, the mutation status BRCA1/2 and general demographic and clinicopathological features of 65 Turkish women diagnosed with TNBC were investigated to elucidate TNBC's complex nature. In this study, TNBC's features were compatible and concordant with the literature regarding parameters such as high Ki-67 index values, diagnosis at an early age and premenopausal period, and mutation status of BRCA1/2 (1-7). In the literature, the BRCA1/2 mutation carrier prevalence of TNBC patients was approximately $10 \%-30 \%$. In this study, the prevalence of BRCA1/2 mutation carriers was $16.9 \%$, consistent with the literature. The age at diagnosis of the patient group was $40.86 \pm 10.28$ years; a statistically significant difference was not found between $B R C A 1 / 2$ mutation non-carriers (40.5) and $B R C A 1 / 2$ mutation carriers (37). In this study, the number of relatives with breast and ovarian cancer was significantly higher in the $B R C A 1 / 2$ mutation carrier group than the non-carrier group. Logistic regression analysis showed that TNBC individuals with relatives with two or more breast and ovarian cancer have a 15-fold increase in the $B R C A 1 / 2$ mutation carrier risk. Studies in the literature have shown that the lifetime risk of breast cancer in females is from $46 \%-87 \%$ in BRCA1 mutation carriers and $38 \%-84 \%$ in BRCA2 mutation cancer up to the age of 70 is from $39 \%-63 \%$ in $B R C A 1$ mutation carriers and from $16.5 \%-27 \%$ in BRCA2 mutation carriers (11-13). In addition to this dramatic increase in risk detected in breast and ovarian cancers, in BRCA1/2 mutation carriers, it has been reported in the literature that there is an increased risk in multiple other cancer types such as pancreas, colon, prostate, buccal cavity, pharynx, kidney, gall bladder, bile duct, cervix, uterine body, bone, stomach, and malignant melanoma. Although BRCA1 and BRCA2 genes both play tumor suppressor roles in the cell, cancers arising from mutations of each of these genes have specific clinicopathological structure. In the literature, these genotype-phenotype correlations were investigated many times. It was determined that observed cancer risks of each of these genes were not the same concerning the age of disease onset, sex, and the primary site of cancer origin (14-21). The diversity in research findings might be due to many reasons, such as insufficient samples, studies in geographically and ethnically different societies, and diversity in analysis systems.

In this study, relatives had 20 different cancer types based on the pedigree analysis of TNBC patients. Twenty-five of 65 patients had at least one relative with breast cancer. At least one relative of 49 patients had a cancer diagnosis (principally breast, lung, colon, stomach, prostate, other types). Regardless of the type of cancer, a significant relationship was found between the number of relatives diagnosed with cancer and BRCA1/2 mutation carrier status. According to the logistic regression model, it was predicted that the risk of carrying $B R C A 1 / 2$ mutation would increase 1.3 times with an increase in the 
Table 2. BRCA1 and BRCA2 genes analysis results

\begin{tabular}{|c|c|c|c|c|c|c|c|c|c|c|c|c|}
\hline ID & Gene & Nuc/AA change & Loc & Func & $\begin{array}{l}\text { ACMG } \\
\text { scoring }\end{array}$ & dbSNP & $\begin{array}{c}\text { Age/ } \\
\text { Age of Dx }\end{array}$ & HPT & $\mathrm{Ki}-67$ & G & BBC & $\begin{array}{l}\text { Cancer history } \\
\text { on relatives }\end{array}$ \\
\hline P3 & $B R C A 1$ & $\begin{array}{c}\text { c.4327C>T } \\
\text { (p.Arg1443Ter) }\end{array}$ & Ex12 & NS & Pat & rs41293455 & $50 / 49$ & IDC & 70 & 3 & - & $\begin{array}{l}\text { 2BC,1OC, 1GC, } \\
1 \mathrm{PrC}, 1 \mathrm{EC}\end{array}$ \\
\hline P4 & $B R C A 1$ & $\begin{array}{c}\text { c.1961delA } \\
\text { (p.Lys654SerfsTer47) }\end{array}$ & Ex10 & FS & Pat & rs80357522 & $55 / 51$ & MC & 75 & 3 & - & $\begin{array}{c}\text { 3BC, } 2 \mathrm{CC}, 1 \mathrm{LC}, \\
2 \mathrm{PrC}, 3 \mathrm{MM}, \\
1 \mathrm{PC}, 1 \mathrm{EC}\end{array}$ \\
\hline P14 & $B R C A 1$ & $\begin{array}{c}\text { c.5098delC } \\
\text { (p.Leu1700Ter) }\end{array}$ & Ex16 & NS & Pat & rs80357896 & $36 / 35$ & IDC & 95 & 3 & - & $1 \mathrm{BC}, 1 \mathrm{LC}, 1 \mathrm{PC}$ \\
\hline P21 & BRCA2 & $\begin{array}{c}\text { c.8395delA } \\
\text { (p.Arg2799AspfsTer22) }\end{array}$ & Ex19 & FS & Pat & rs80359709 & $46 / 32$ & IDC & 90 & 3 & - & $1 \mathrm{BC}, 1 \mathrm{LC}, 1 \mathrm{BrC}$ \\
\hline P28 & $B R C A 1$ & $\begin{array}{c}\text { c.5507G>A } \\
\text { (р.Trр1836Ter) }\end{array}$ & Ex22 & NS & Pat & rs80356962 & $31 / 30$ & IDC & 90 & 3 & - & $1 \mathrm{BC}, 1 \mathrm{GC}$ \\
\hline P30 & $B R C A 1$ & $\begin{array}{c}\text { c.3844G>T } \\
\text { (p.Glu1282Ter) }\end{array}$ & Ex10 & NS & Pat & Novel & $52 / 50$ & IDC & 30 & 3 & - & $\begin{array}{l}1 \mathrm{BC}, 1 \mathrm{BrC}, 1 \mathrm{CC} \\
1 \mathrm{BrC}, 1 \mathrm{CC}, 3 \mathrm{LC}\end{array}$ \\
\hline P39 & $B R C A 2$ & $\begin{array}{l}\text { c.1773_1776delTTAT } \\
\text { (p.lle591MetfsTer22) }\end{array}$ & Ex10 & FS & Pat & rs80359304 & $55 / 40$ & IDC & 70 & 3 & + & $\begin{array}{l}\text { 2BC, } 1 \mathrm{LC}, 1 \mathrm{EC} \\
1 \mathrm{GC}, 1 \mathrm{LxC}\end{array}$ \\
\hline P41 & $B R C A 1$ & $\begin{array}{c}\text { c.4307_4308delct } \\
\text { (p.Ser1436PhefsTer4) }\end{array}$ & Ex12 & FS & Pat & rs397509161 & $30 / 27$ & IDC & 90 & 3 & - & $3 B C$ \\
\hline P48 & $B R C A 2$ & $\begin{array}{c}\text { NM_000059:c.7710_7711delGG } \\
\text { (p.Glu2571LysfsTer12) }\end{array}$ & Ex16 & FS & Pat & Novel & $38 / 37$ & IDC & 80 & 3 & - & - \\
\hline P51 & $B R C A 2$ & $\begin{array}{c}\text { c.5969delA } \\
\text { (p.Asp1990ValfsTer) }\end{array}$ & Ex11 & FS & Pat & rs886038135 & $47 / 45$ & IDC & NA & NA & - & - \\
\hline P60 & $B R C A 1$ & $\begin{array}{c}\text { c.5314C>T } \\
\text { (p.Arg1772Ter) }\end{array}$ & Ex19 & NS & Pat & rs80357123 & $30 / 26$ & IDC & 40 & 3 & - & $1 \mathrm{EC}, 1 \mathrm{CC}$ \\
\hline
\end{tabular}

Loc: Localization; Ex: Exon; Func: Function; Nuc: Nucleotide; AA: Aminoacide; NS: Nonsense; FS: Frameshift; Pat: Pathogenic; Dx: Diagnoses; HPT: Histopathologic type; IDC: Invasive Ductal Carcinoma; MC: Medullary Carcinoma; G: Grade; NA: Not available; BBC: Bilateral breast cancer; BC: Breast cancer; OC: Ovarian cancer; GC: Gastric cancer; PrC: Prostate cancer; PC: Pancreas cancer; EC: Endometrium cancer; CC: Colon cancer; LC: Lung cancer; MM: Malign Melanoma; BrC: Brain cancer; LxC: Larynx cancer; ACMG: American College of Medical Genetics and Genomics

Table 3. Relationship of variables with $B R C A 1 / 2$ mutation carrier status

\begin{tabular}{|c|c|c|c|c|c|}
\hline \multirow[t]{2}{*}{ Variable } & \multicolumn{2}{|c|}{$\begin{array}{c}B R C A 1 / 2 \text { non-carriers } \\
(n=54)\end{array}$} & \multicolumn{2}{|c|}{$\begin{array}{l}\text { BRCA1/2 mutation carriers } \\
\qquad(\mathrm{n}=11)\end{array}$} & \multirow[t]{2}{*}{ p-value } \\
\hline & $n$ & $\%$ & $\mathbf{n}$ & $\%$ & \\
\hline \multicolumn{6}{|l|}{ Age } \\
\hline$\leq 40$ & 18 & 33 & 5 & 46 & \multirow{2}{*}{0.443} \\
\hline$>40$ & 36 & 67 & 6 & 54 & \\
\hline \multicolumn{6}{|l|}{ Age at diagnosis } \\
\hline$\leq 40$ & 27 & 50 & 7 & 64 & \multirow{2}{*}{0.409} \\
\hline$>40$ & 27 & 50 & 4 & 36 & \\
\hline \multicolumn{6}{|l|}{ Right/left } \\
\hline Right & 27 & 50 & 4 & 36 & \multirow{3}{*}{0.481} \\
\hline Left & 19 & 35 & 6 & 55 & \\
\hline Bilateral & 8 & 15 & 1 & 9 & \\
\hline \multicolumn{6}{|l|}{ Level of education } \\
\hline Elementary school & 21 & 39 & 6 & 55 & \multirow{3}{*}{0.394} \\
\hline High school & 18 & 33 & 4 & 36 & \\
\hline University & 15 & 28 & 1 & 9 & \\
\hline \multicolumn{6}{|l|}{ Chronic disease } \\
\hline No & 39 & 72 & 5 & 46 & \multirow[t]{2}{*}{0.084} \\
\hline Yes & 15 & 29 & 6 & 54 & \\
\hline
\end{tabular}


Table 3. Continued

\begin{tabular}{|c|c|c|c|c|c|}
\hline \multirow[t]{2}{*}{ Variable } & \multicolumn{2}{|c|}{$\begin{array}{c}B R C A 1 / 2 \text { non-carriers } \\
(\mathrm{n}=54)\end{array}$} & \multicolumn{2}{|c|}{$\begin{array}{l}\text { BRCA1/2 mutation carriers } \\
\qquad(\mathrm{n}=11)\end{array}$} & \multirow[t]{2}{*}{ p-value } \\
\hline & $\mathbf{n}$ & $\%$ & $\mathbf{n}$ & $\%$ & \\
\hline \multicolumn{6}{|l|}{ Surgery history } \\
\hline No & 37 & 69 & 8 & 73 & \multirow[t]{2}{*}{0.783} \\
\hline Yes & 17 & 31 & 3 & 27 & \\
\hline \multicolumn{6}{|l|}{ Menstrual period } \\
\hline Irregular & 8 & 15 & - & - & \multirow[t]{2}{*}{0.173} \\
\hline Regular & 46 & 85 & 11 & 100 & \\
\hline \multicolumn{6}{|l|}{ Living place } \\
\hline Rural & 9 & 17 & 2 & 18 & \multirow[t]{2}{*}{0.903} \\
\hline City & 45 & 83 & 9 & 82 & \\
\hline \multicolumn{6}{|l|}{ Grade } \\
\hline$\leq 2$ & 15 & 28 & - & - & \multirow[t]{2}{*}{0.055} \\
\hline 3 & 39 & 72 & 11 & 100 & \\
\hline \multicolumn{6}{|l|}{ Metastasis at diagnosis } \\
\hline No & 34 & 64 & 8 & 73 & \multirow[t]{2}{*}{0.432} \\
\hline Yes (localized, regional, axiller) & 19 & 36 & 3 & 27 & \\
\hline \multicolumn{6}{|l|}{ Marital status } \\
\hline Single & 5 & 9 & 2 & 18 & \multirow{3}{*}{0.628} \\
\hline Married & 48 & 89 & 9 & 82 & \\
\hline Widow & 1 & 2 & - & - & \\
\hline \multicolumn{6}{|l|}{ Number of children } \\
\hline None & 7 & 13 & 4 & 36 & \multirow{4}{*}{0.058} \\
\hline 1 & 10 & 19 & - & - & \\
\hline 2 & 31 & 57 & 4 & 36 & \\
\hline$\geq 3$ & 6 & 11 & 3 & 28 & \\
\hline The number of relatives with cancer & 36 & 67 & 3 & 28 & \multirow{4}{*}{0.021} \\
\hline None & 13 & 24 & 4 & 36 & \\
\hline 1 & 5 & 9 & 4 & 36 & \\
\hline$\geq 2$ & & & & & \\
\hline
\end{tabular}

Table 4. Comparison of parameters according to BRCA1/2 mutation carrier status

\begin{tabular}{|c|c|c|c|c|c|}
\hline \multirow{2}{*}{ Variable } & \multicolumn{2}{|c|}{$\begin{array}{c}\text { BRCA1/2 non-carriers } \\
(n=54)\end{array}$} & \multicolumn{2}{|c|}{$\begin{array}{l}\text { BRCA1/2 mutation carriers } \\
\text { ( }(\mathrm{n}=11)\end{array}$} & \multirow{2}{*}{ p-value } \\
\hline & $\overline{\mathbf{X}} \pm S D$ & Median & $\overline{\mathbf{X}} \pm S D$ & Median & \\
\hline Age (year) & $46 \pm 10$ & 47.0 & $43 \pm 10$ & 46.0 & 0.411 \\
\hline Age at diagnosis (year) & $41 \pm 10$ & 41.0 & $38 \pm 9$ & 37.0 & 0.407 \\
\hline Ki-67 & $49 \pm 29$ & 40.0 & $73 \pm 22$ & 78.0 & 0.022 \\
\hline NOR with BC/OC & $0 \pm 0$ & 0.0 & $1 \pm 1$ & 1.0 & 0.006 \\
\hline NOR with ATC & $2 \pm 2$ & 2.0 & $4 \pm 4$ & 3.0 & 0.047 \\
\hline
\end{tabular}


Table 5. Logistic regression model for $B R C A 1 / 2$ mutation carrier risk status of relatives with breast/ovarian cancer

\begin{tabular}{llccc}
\hline Variable & P-value & OR & $\begin{array}{c}\text { 95\% Confidence interval (OR)* } \\
\text { (min-max) }\end{array}$ \\
\hline FH of breast/ovary Ca - None & & - & - & - \\
$\mathbf{1}$ & 0.026 & 4.12 & 0.77 & 21.96 \\
$\geq 2$ & 0.097 & 15.13 & 2.06 & - \\
Constant & $\mathbf{0 . 0 0 8}$ & 0.84 & \\
\hline Significant p-values are shown in bold. *Binary logistic regression, Backward: LR model was used. & & \\
OR: Odds ratio; Ca: Cancer; FH: Family history; min: Minimum; max: Maximum &
\end{tabular}

Table 6. Logistic regression model for BRCA1/2 mutation carrier risk status of relatives with all types of cancers

\begin{tabular}{|lllll|}
\hline Variable & p-value & OR & $\begin{array}{r}\text { 95\% Confid } \\
\text { Interval ( } \\
\text { (min-m }\end{array}$ \\
\hline $\begin{array}{l}\text { FH of all types of } \\
\text { cancers }\end{array}$ & 0.031 & 1.31 & 1.03 & 1.68 \\
Constant & 0.000 & 0.09 & - & - \\
\hline
\end{tabular}

Significant $\mathrm{p}$-values are shown in bold. *Binary logistic regression, Backward: LR model was used.

FH: Family history; OR: Odds ratio; min: Minimum; max: Maximum

number of each relative with cancer for TNBC patients.

This study's limitations are that the sample group was not large enough, and co-segregation analysis could not be performed for all patients' relatives. Information about a cancer diagnosis in patients' relatives was obtained from the pedigree analysis, and pathological reports of most of them could not be reached. Also, environmental factors that may predispose relatives to cancer could not be investigated. In conclusion, TNBC is a heterogeneous cancer type that occurs at an early age, has a poor prognosis, and high histopathologic grade.

In this study, we investigated the relationship between TNBC and $B R C A 1 / 2$ mutation carrier status of 65 patients. We found a significant relationship between $B R C A 1 / 2$ mutation carrier status, high Ki-67 index, and the number of relatives with cancer. In the future, further research is needed to determine the importance of these genes in TNBC and help elucidate the complex nature of TNBC.

\section{Acknowledgments}

The authors thank colleagues in the Dr. Abdurrahman Yurtaslan Ankara Oncology Training and Research Hospital, Department of Medical Genetics and Department of Medical Pathology.

Ethics Committee Approval: The present study involved human participants, and it was conducted considering ethical responsibilities according to the World Medical Association and the Declaration of Helsinki. The independent Ethics Committee of the Dr. Abdurrahman Yurtaslan Ankara Oncology Training and Research Hospital approved this study (no: 2020-02/536).
Informed Consent: Written informed consent was obtained from patients who participated in this study.

Peer-review: Externally peer-reviewed.

\section{Author Contributions}

Concept: N.D.; Design: N.D.; Supervision: N.D.; Resources: N.D.; Materials: N.D., O.K.; Data Collection and/or Processing: N.D., O.K.; Analysis and/ or Interpretation: N.D.; Literature Search: N.D.; Writing Manuscript: N.D.; Critical Review: N.D., O.K.

Conflict of Interest: The authors have no conflicts of interest to declare.

Financial Disclosure: The authors declared that this study has received no financial support.

\section{References}

1. Bray F, Ferlay J, Soerjomataram I, Siegel RL, Torre LA, Jemal A. Global cancer statistics 2018: GLOBOCAN estimates of incidence and mortality worldwide for 36 cancers in 185 countries. CA Cancer J Clin 2018; 68: 394-424. (PMID: 30207593) [CrossRef]

2. Stevens KN, Vachon CM, Couch FJ. Genetic susceptibility to triplenegative breast cancer. Cancer Res 2013; 73: 2025-2030. (PMID: 23536562) [CrossRef]

3. Kumar P, Aggarwal R. An overview of triple-negative breast cancer. Arch Gynecol Obstet 2016; 293: 247-269. (PMID: 26341644) [CrossRef]

4. Pan Y, Yuan Y, Liu G, Wei Y. P53 and Ki-67 as prognostic markers in triple-negative breast cancer patients. PLoS One 2017; 12: e0172324. (PMID: 28235003) [CrossRef]

5. Lippi G, Mattiuzzi C, Montagnana M. BRCA population screening for predicting breast cancer: for or against? Ann Transl Med 2017; 5: 275. (PMID: 28758101) [CrossRef]

6. Li YT, Ni D, Yang L, Zhao Q, Ou JH. The prevalence of BRCA1/2 mutations of triple-negative breast cancer patients in Xinjiang multiple ethnic region of China. Eur J Med Res 2014; 19: 35. (PMID: 24961674) [CrossRef]

7. Muendlein A, Rohde BH, Gasser K, Haid A, Rauch S, Kinz E, et al. Evaluation of BRCA1/2 mutational status among German and Austrian women with triple-negative breast cancer. J Cancer Res Clin Oncol 2015; 141: 2005-2012. (PMID: 25971625) [CrossRef]

8. Beck AC, Yuan H, Liao J, Imperiale P, Shipley K, Erdahl LM, et al. Rate of BRCA mutation in patients tested under NCCN genetic testing criteria. Am J Surg 2020; 219: 145-149. (PMID: 31255259) [CrossRef]

9. Elston CW, Ellis IO. Pathological prognostic factors in breast cancer. I. The value of histological grade in breast cancer: experience from a large 
study with long-term follow-up. Histopathology 1991; 19: 403-410. (PMID: 1757079) [CrossRef]

10. Richards S, Aziz N, Bale S, Bick D, Das S, Gastier-Foster J, et al. Standards and guidelines for the interpretation of sequence variants: A joint consensus recommendation of the American College of Medical Genetics and Genomics and the Association for Molecular Pathology. Genet Med 2015; 17: 405-424. (PMID: 25741868) [CrossRef]

11. Diaz Casas S, Lancheros García E, Sanchéz Campo A, Sanchez Pedraza R, Roman Vasquez V, Mendoza SD, et al. Clinical behavior of triple negative breast cancer in a cohort of Latin American women. Cureus 2019; 11 : e4963. (PMID: 31453035) [CrossRef]

12. Cinkaya A, Akin M, Sengul A. Evaluation of treatment outcomes of triple-negative breast cancer. J Cancer Res Ther 2016; 12: 150-154. (PMID: 27072229) [CrossRef]

13. Duzkale N, Eyerci N, Oksuzoglu B, Teker T, Kandemir O. Novel BRCA2 pathogenic genotype and breast cancer phenotype discordance in monozygotic triplets. Eur J Med Genet 2020; 63: 103771. (PMID: 31563594) [CrossRef]

14. Petrucelli N, Daly MB, Pal T. BRCA1- and BRCA2-associated hereditary breast and ovarian cancer. 1998 Sep 4 [Updated 2016 Dec 15]. In: Adam MP, Ardinger HH, Pagon RA, Wallace SE, Bean LJH, Mirzaa G, et al, editors. GeneReviews ${ }^{\bullet}$ [Internet]. Seattle, WA: University of Washington: Seattle; 1993-2020. [CrossRef]

15. Duzkale N, Teker T. The study of genetic and clinicopathologic characterization of Turkish bilateral breast cancer patients. Oncology Clin Pract 2020; 16: 1-8. [CrossRef]
16. Streff H, Profato J, Ye Y, Nebgen D, Peterson SK, Singletary C, et al. Cancer incidence in first- and second-degree relatives of BRCA1 and BRCA2 mutation carriers. Oncologist 2016; 21: 869-874. (PMID: 27306910) [CrossRef]

17. Noh JM, Choi DH, Baek H, Nam SJ, Lee JE, Kim JW, et al. Associations between BRCA mutations in high-risk breast cancer patients and familial cancers other than breast or ovary. J Breast Cancer 2012; 15: 283-287. (PMID: 23091540) [CrossRef]

18. Lorenzo Bermejo J, Hemminki K. Risk of cancer at sites other than the breast in Swedish families eligible for BRCA1 or BRCA2 mutation testing. Ann Oncol 2004; 15: 1834-1841. (PMID:15550590) [CrossRef]

19. Mersch J, Jackson MA, Park M, Nebgen D, Peterson SK, Singletary C, et al. Cancers associated with BRCA1 and BRCA2 mutations other than breast and ovarian. Cancer 2015; 121: 269-275. (PMID: 25224030) [CrossRef]

20. Digennaro M, Sambiasi D, Tommasi S, Pilato B, Diotaiuti S, Kardhashi A, et al. Hereditary and non-hereditary branches of family eligible for BRCA test: cancers in other sites. Hered Cancer Clin Pract 2017; $15: 7$. (PMID: 28559958) [CrossRef]

21. Friedenson B. BRCA1 and BRCA2 pathways and the risk of cancers other than breast or ovarian. MedGenMed 2005; 7: 60. (PMID:16369438) [CrossRef] 